\title{
Comparação entre métodos de tuberculinização no diagnóstico da infecção por agentes do complexo Mycobacterium avium ou M. bovis em suínos
}

[Comparative study of methods of tuberculin skin test with the avium and bovine tuberculin in the diagnosis of the infection by agents of the Mycobacterium avium-complex or M. bovis in swine]

\author{
N. Morés, A.L. Amaral, L. Ventura, R.A.M. Silva, V.S. Silva, W. Barioni Junior \\ Embrapa Suínos e Aves \\ Caixa Postal 21 \\ 89700-000 - Concórdia, SC
}

\begin{abstract}
RESUMO
Avaliou-se a eficiência do teste de tuberculina intradérmico comparado, para identificar rebanhos suínos infectados com o complexo Mycobacterium avium (MAC), seu poder de discriminação entre rebanhos infectados com MAC e Mycobacterium bovis, e para estudar diferentes critérios de leitura e interpretação. Foram realizados três experimentos com rebanhos infectados naturalmente com MAC, com suínos inoculados com MAC e com suínos inoculados com M. bovis. Os testes foram comparados com a presença ou não de lesões macro e/ou microscópicas nos linfonodos de suínos em idade de abate. Verificaram-se reações cruzadas entre os testes intradérmicos, tanto com animais infectados com o MAC como com M. bovis. Reações acima de $0,5 \mathrm{~cm}$ de diâmetro ou acima de $0,20 \mathrm{~cm}$ no aumento da espessura da dobra da pele, entre a aplicação e a leitura, foram consideradas positivas no cálculo da média para rebanhos. Rebanhos infectados com MAC podem ser identificados por meio do teste intradérmico com PPD aviário e bovino. Tanto a medida do diâmetro quanto o aumento da espessura da dobra da pele das reações foram eficientes no diagnóstico da infecção por MAC. Recomenda-se a utilização do método da medição do diâmetro.
\end{abstract}

Palavras-chave: suínos, tuberculina, Mycobacterium avium, Mycobacterium bovis

\begin{abstract}
The efficiency of the tuberculin delayed-type skin hypersensitivity test was evaluated in swine. A comparison of the tuberculin skin tests was performed with avian and bovine protein derivatives (PPD), in the detection of Mycobacterium avium-Complex or $\mathrm{M}$. bovis infected swine. The methods were evaluated as to define criteria for readings and results interpretation, to determine their capacity in detecting Mycobacterium avium complex (MAC) infected swine and their performance in differentiating $M A C$ from M. bovis-infected individuals. Three trials were performed with naturally MAC-infected swine, experimentally MAC-infected or experimentally $\mathrm{M}$. bovis-infected animals. The skin test readings positive or negative were, respectively, correlated to the presence or absence of gross lesions and histological alterations in lymph nodes at slaughter age. Reaction with both antigens were observed in MAC and M. bovis-inoculated animals as well. Reactions wider then $0.5 \mathrm{~cm}$ in diameter or showing skin thickness increasing more then $0.2 \mathrm{~cm}$ in the time frame between inoculation and reading were considered to be positive, as compared to the average results of the group. Herds with MAC-infected swine could be detected with either avian or bovine PPD. Both diameter and skin thickness were efficient in detecting
\end{abstract}

Recebido em 24 de setembro de 2004

Aceito em 25 de novembro de 2005

E-mail: mores@cnpsa.embrapa.br 
MAC-infected swine, however, reading the diameter of the reaction was shown to be more easily and economically performed.

Keywords: swine, tuberculin, Mycobacterium avium, Mycobacterium bovis

\section{INTRODUÇÃO}

A linfadenite granulomatosa em suínos, associada à infecção pelo complexo Mycobacterium avium (MAC), é uma doença de importância econômica, mas não provoca qualquer sintoma e nem afeta o desenvolvimento dos animais (Thoen, 1992). Seu impacto econômico na suinocultura da região Sul do Brasil, devido à condenação ou ao destino condicionado das carcaças afetadas, foi estimado em 5,8, 7,0 e 8,0 milhões de reais em 1997, 1998 e 1999, respectivamente (Martins, 2001).

O diagnóstico da infecção ainda apresenta dificuldades, não existindo um teste prático e eficiente para dar suporte aos estudos epidemiológicos e às estratégias de controle (Pullar e Rusford, 1954; Prichard et al. 1977; Thoen, 1992; Cavirani et al., 1996).

As lesões macro e microscópicas observadas nos linfonodos são do tipo granulomatosas (Senk et al. , 1992; Cavirani et al., 1996), mas também não são conclusivas, uma vez que podem ser provocadas por outras bactérias, em especial o M. bovis (Thoen, 1992). O isolamento do MAC exige procedimentos de laboratório especiais, demanda muito tempo com custo elevado e apresenta baixo poder de detecção (Prichard et al. 1977), atribuída aos procedimentos de descontaminação dos tecidos (Silva, 1998).

O diagnóstico in vivo conta apenas com o teste de tuberculina intradérmico comparado, com derivados protéicos purificados (PPD) aviário e bovino, porém existem divergências entre diferentes autores quanto aos critérios de aplicação, leitura e interpretação do teste em suínos (Charette et al. 1989; Thoen, 1992; Cavirani et al., 1996), dificultando sua utilização. O objetivo deste trabalho foi avaliar a eficiência do teste de tuberculina intradérmico comparado para identificar rebanhos suínos infectados por micobactérias, discriminar rebanhos infectados com MAC daqueles com o $M$. bovis e identificar o melhor método de medição da reação ao teste intradérmico comparado.

\section{MATERIAL E MÉTODOS}

Experimento 1. Utilizaram-se seis rebanhos suínos comerciais com histórico de lesões de linfadenite granulomatosa no abate. $\mathrm{O}$ teste intradérmico comparado, com tuberculina PPD aviária e bovina, foi realizado em lotes de suínos cerca de uma semana antes do abate (entre 100 e $120 \mathrm{~kg}$ ). Os suínos que apresentavam qualquer reação às tuberculinas e alguns sem reação (controle negativo) também foram abatidos em menos de sete dias após a aplicação do teste, para avaliação de lesões nos linfonodos e colheita de amostras para exames laboratoriais.

Experimento 2. Para o teste intradérmico comparado, utilizaram-se 64 leitões que vieram de um rebanho livre de patógenos específicos (SPF). Os leitões, colocados no isolamento do laboratório de sanidade da Embrapa Suínos e Aves, foram inoculados por via oral com a cepa SC1 de MAC suspendida em caldo BHI. Para medição do diâmetro da reação, foram utilizados 44 leitões com idade média de 42 dias, inoculados com $5 \mathrm{ml} \mathrm{de} \mathrm{BHI,} \mathrm{contendo} \mathrm{diferentes}$ concentrações de MAC (de 0,0002 a 2,0mg de massa bacteriana por ml) com objetivo de obter maior variabilidade das reações às tuberculinas e das lesões macro e microscópicas. Para a medida da espessura da dobra da pele, foram utilizados 20 leitões, com idade média de 54 dias, inoculados com $5 \mathrm{ml}$ de BHI contendo $2,0 \mathrm{mg} / \mathrm{ml}$ da massa bacteriana de MAC. O teste intradérmico com tuberculina PPD aviária e bovina foi realizado com aproximadamente 160 dias de idade. Em seguida, os leitões foram abatidos para avaliação de lesões nos linfonodos e colheita de amostras para exames de laboratório.

Experimento 3. Utilizaram-se 12 leitões de um rebanho SPF do laboratório de sanidade da Embrapa Suínos e Aves, com idade média de 41 dias. Oito leitões foram inoculados por via intranasal com 2,0mg de massa bacteriana de uma amostra patogênica de $M$. bovis isolada de suínos, e quatro permaneceram não inoculados (controle). Em todos os suínos, o teste 
intradérmico comparado e o abate foram realizados 38 e 40 dias após a inoculação, respectivamente.

Em todos os experimentos, os suínos receberam, por via intradérmica, $0,1 \mathrm{ml}$ de tuberculina aviária $(0,05 \mathrm{mg} \text { de PPD - } 2500 \mathrm{UI})^{1}$, na face dorsal da orelha esquerda (Fig. 1), e $0,1 \mathrm{ml}$ de tuberculina bovina $(0,1 \mathrm{mg}$ de PPD), na face dorsal da orelha direita. Para aplicação das tuberculinas, utilizaram-se seringas e agulhas para aplicação de insulina em humanos. A leitura foi realizada cerca de 48 horas após a aplicação por meio de dois métodos: a) medição do diâmetro da reação, utilizando-se uma régua milimétrica, considerando a maior medida nas reações irregulares; b) medição do aumento da espessura da dobra da pele realizada com cutímetro, na aplicação e 48 horas após, calculado pela diferença entre as duas medidas.

No abate, os suínos foram avaliados macroscopicamente quanto à presença de lesões granulomatosas, e foram colhidas amostras de linfonodos submandibulares e do mesentério para isolamento de micobactérias e exames histológico e imunoperoxidase (Morés et al., 2001), para confirmação da infecção. Nos exames bacteriológicos para isolamento de micobactérias, utilizaram-se o método de descontaminação de Petroff, semeadura em meio de Lowenstain Jensen e incubação a $37^{\circ} \mathrm{C}$ por 60 dias (Silva, 1998), com caracterização de espécie pela técnica de PCR. No teste de imunoperoxidase (experimentos 1 e 2), utilizouse anticorpo monoclonal produzido com extrato celular de $M$. avium $^{1}$. Os exames de isolamento de micobactérias e de imunoperoxidase foram realizados apenas em alguns suínos por granja e por experimento para confirmação da infecção.

Para obter o melhor ponto de corte na interpretação das reações às tuberculinas, foi utilizado o teste Kappa, com nível de confiança de $95 \%$ e três diferentes pontos de corte das reações, tanto para o diâmetro como para o aumento da espessura da pele (Win..., 2004). A comparação das médias entre as reações à tuberculina aviária e à bovina foi realizada pelo teste Tukey (System..., 2001).

\section{RESULTADOS E DISCUSSÃO}

A infecção por MAC foi confirmada pelo exame macroscópico (Fig. 2), isolamento, histologia (Fig. 3) e imunoperoxidase (Fig. 4) nas seis granjas do experimento 1 e nos suínos inoculados do experimento 2 . No experimento 3 , a infecção com o $M$. bovis foi confirmada pelo isolamento do agente dos pulmões.

A concordância observada entre o diâmetro maior da reação à tuberculina PPD aviária, com o exame patológico nos suínos infectados naturalmente com MAC, foi 53,3\%, 84,4\% e $89,3 \%$, quando se consideraram como positivos os animais com reações superiores a $2,0 \mathrm{~cm}$, $1,0 \mathrm{~cm}$ e $0,5 \mathrm{~cm}$, respectivamente (Tab. 1). Com os suínos inoculados experimentalmente com MAC, a concordância entre os testes foi de $79,5 \%, 86,4 \%$ e $81,8 \%$, quando se consideraram como positivas as reações à tuberculina PPD aviária superiores a $2,0 \mathrm{~cm}, 1,0 \mathrm{~cm}$ e $0,5 \mathrm{~cm}$ de diâmetro, respectivamente (Tab. 2). Nas Fig. 5 e 6 , mostram-se, respectivamente, a medição do diâmetro maior da reação com a tuberculina PPD aviária e a reação cruzada existente entre as duas tuberculinas testadas. Houve variação no tamanho das reações às tuberculinas aplicadas em função da dose de MAC usada como inóculo: as reações variaram de $0,00 \mathrm{~cm}$ a $2,83 \mathrm{~cm}$ e de $0,00 \mathrm{~cm}$ a $2,00 \mathrm{~cm}$ no diâmetro maior, com doses de $0,0002 \mathrm{mg}$ a $2,0 \mathrm{mg}$ de massa bacteriana $/ \mathrm{ml}$ de inóculo, respectivamente.

Com relação ao aumento da espessura da dobra da pele em suínos infectados naturalmente, a concordância com o exame patológico foi de $68,2 \%, 75,0 \%$ e $79,5 \%$, quando se consideraram como positivos valores superiores a $0,50 \mathrm{~cm}$, $0,30 \mathrm{~cm}$ e $0,20 \mathrm{~cm}$, respectivamente (Tab. 3 ). Nos suínos inoculados experimentalmente (Tab. 4), a concordância foi $40,0 \%, 85,0 \%$ e $95,0 \%$, quando se consideraram como positivos valores superiores a $0,50 \mathrm{~cm}, 0,30 \mathrm{~cm}$ e $0,20 \mathrm{~cm}$, respectivamente.

\footnotetext{
${ }^{1}$ Tecpar $^{\circledR}$ - Curitiba - Brasil
} 


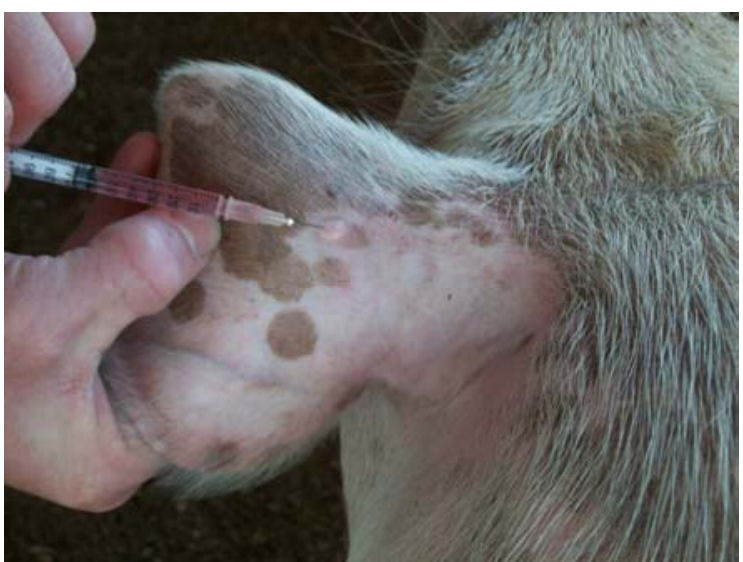

Figura 1. Aplicação intradérmica da tuberculina (formação de lentilha) em suíno, usando agulha e seringa de insulina.

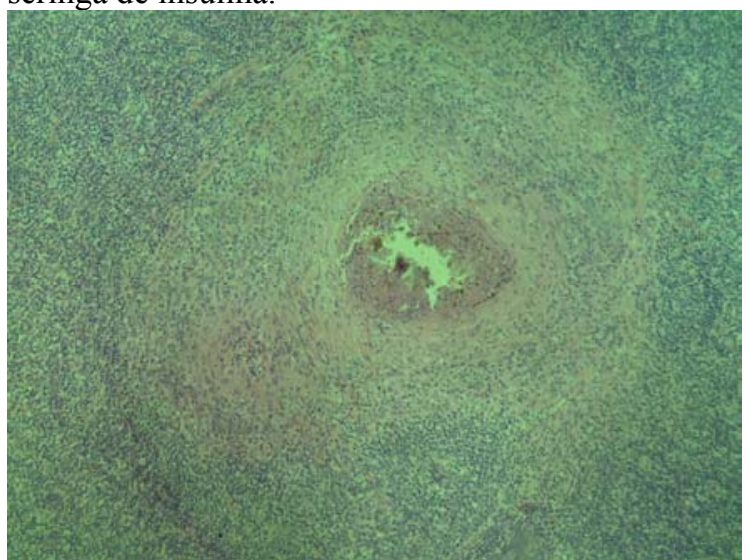

Figura 3. Linfonodos mesentéricos de suíno Figura 4. Reação positiva ao teste de inoculado com MAC: lesão microscópica de imunoperoxidase (cor marrom) em linfonodo de linfadenite granulomatosa.

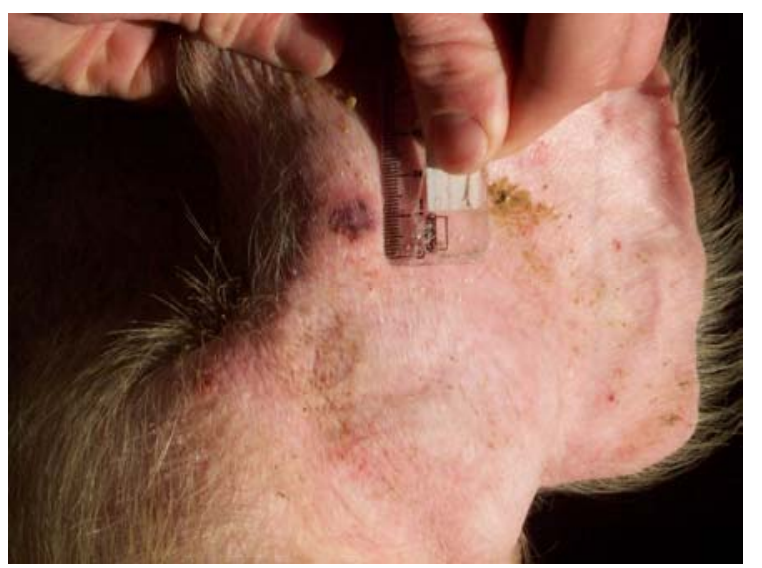

Figura 5. Suíno inoculado com MAC com reação à Figura 6. Suíno inoculado com MAC: reação tuberculina aviária; medida do diâmetro da reação, positiva à tuberculina aviária (orelha direita) com régua, 48 horas após à aplicação.

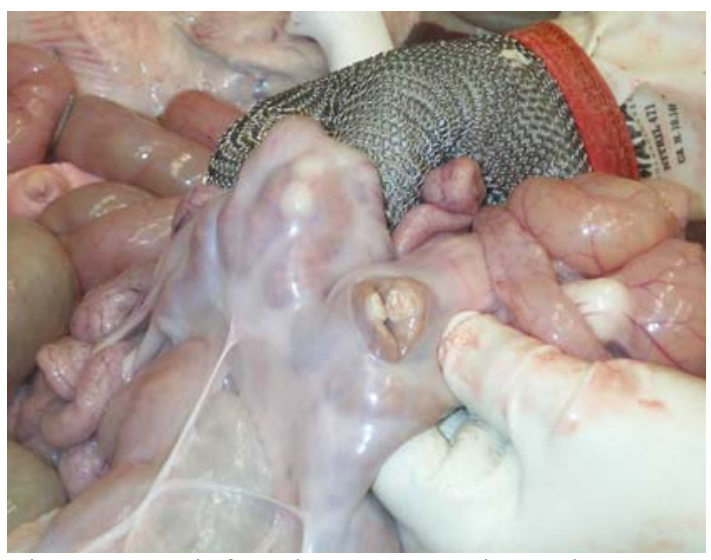

Figura 2. Linfonodos mesentéricos de suíno inoculado com MAC, apresentando lesões granulomatosas de linfadenite.

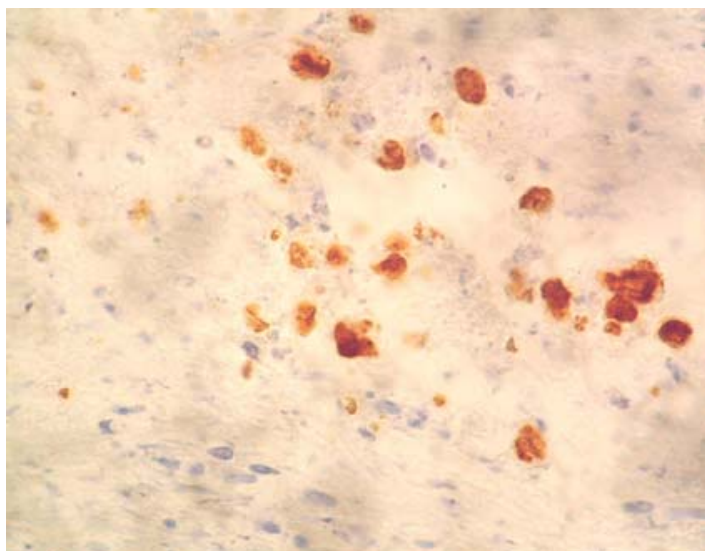
suíno inoculado com MAC.

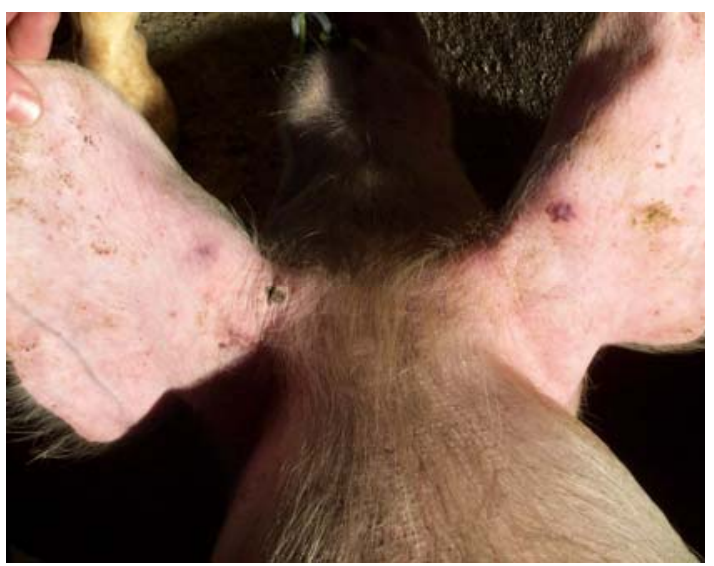

maior que a reação à bovina (orelha esquerda). 
Tabela 1. Teste de concordância entre o teste com a tuberculina (tub.) PPD aviária, pela medição do diâmetro da reação, e o exame patológico, em suínos infectados naturalmente com MAC

\begin{tabular}{|c|c|c|c|c|c|c|}
\hline \multirow[t]{2}{*}{ Teste } & \multirow{2}{*}{$\begin{array}{l}\text { Critério usado } \\
\text { (ponto de corte) }\end{array}$} & \multicolumn{2}{|c|}{$\begin{array}{c}\text { Exames macro } \\
\text { e/ou micro }\end{array}$} & \multirow[t]{2}{*}{ Total } & \multirow{2}{*}{$\begin{array}{l}\text { Kappa } \\
\text { (IC) }\end{array}$} & \multirow{2}{*}{$\begin{array}{l}\text { Concordância } \\
\text { observada (\%) }\end{array}$} \\
\hline & & Positivo* & Negativo & & & \\
\hline \multirow{3}{*}{$\begin{array}{l}\text { Reação à tub. } \\
\text { aviária }\end{array}$} & Positivo: $>2,0 \mathrm{~cm}$ & 53 & 0 & 53 & 0,155 & \multirow{3}{*}{53,3} \\
\hline & Negativo: $\leq 2,0 \mathrm{~cm}$ & 57 & 12 & 69 & $(0,060-0,249)$ & \\
\hline & Total & 110 & 12 & 122 & & \\
\hline \multirow{3}{*}{$\begin{array}{l}\text { Reação à tub. } \\
\text { aviária }\end{array}$} & Positivo: $>1,0 \mathrm{~cm}$ & 99 & 8 & 107 & 0,210 & \multirow{3}{*}{84,4} \\
\hline & Negativo: $\leq 1,0 \mathrm{~cm}$ & 11 & 4 & 15 & $(0,034-0,386)$ & \\
\hline & Total & 110 & 12 & 122 & & \\
\hline \multirow{3}{*}{$\begin{array}{l}\text { Reação à tub. } \\
\text { aviária }\end{array}$} & Positivo: $>0,5 \mathrm{~cm}$ & 108 & 11 & 119 & 0,098 & \multirow{3}{*}{89,3} \\
\hline & Negativo: $\leq 0,5 \mathrm{~cm}$ & 2 & 1 & 3 & $(-0,041-0,236)$ & \\
\hline & Total & 110 & 12 & 122 & & \\
\hline
\end{tabular}

*Considerou-se como reação positiva a presença de granulomas unicêntricos ou multicêntricos, com ou sem mineralização central, ou a presença de histiócitos, com ou sem formação de células multinucleadas.

$\mathrm{IC}=$ intervalo de confiança.

Tabela 2. Teste de concordância entre o exame com tuberculina (tub.) PPD aviária, pela medição do diâmetro da reação, e o exame patológico, em suínos infectados experimentalmente com MAC

\begin{tabular}{|c|c|c|c|c|c|c|}
\hline \multirow[t]{2}{*}{ Teste } & \multirow{2}{*}{$\begin{array}{l}\text { Critério usado } \\
\text { (ponto de corte) }\end{array}$} & \multicolumn{2}{|c|}{$\begin{array}{c}\text { Exames macro } \\
\text { e/ou micro }\end{array}$} & \multirow[t]{2}{*}{ Total } & \multirow{2}{*}{$\begin{array}{l}\text { Kappa } \\
\text { (IC) }\end{array}$} & \multirow{2}{*}{$\begin{array}{l}\text { Concordância } \\
\text { observada (\%) }\end{array}$} \\
\hline & & Positivo* & Negativo & & & \\
\hline \multirow{3}{*}{$\begin{array}{l}\text { Reação à tub. } \\
\text { aviária }\end{array}$} & Positivo: $>2,0 \mathrm{~cm}$ & 24 & 1 & 25 & \multirow{3}{*}{$\begin{array}{c}0,564 \\
(0,286-0,842)\end{array}$} & \multirow{3}{*}{79,5} \\
\hline & Negativo: $\leq 2,0 \mathrm{~cm}$ & 8 & 11 & 19 & & \\
\hline & Total & 32 & 12 & 44 & & \\
\hline \multirow{3}{*}{$\begin{array}{l}\text { Reação à tub. } \\
\text { aviária }\end{array}$} & Positivo: $>1,0 \mathrm{~cm}$ & 31 & 5 & 36 & 0,616 & \multirow{3}{*}{86,4} \\
\hline & Negativo: $\leq 1,0 \mathrm{~cm}$ & 1 & 7 & 8 & $(0,331-0,902)$ & \\
\hline & Total & 32 & 12 & 44 & & \\
\hline \multirow{3}{*}{$\begin{array}{l}\text { Reação à tub. } \\
\text { aviária }\end{array}$} & Positivo: $>0,5 \mathrm{~cm}$ & 31 & 7 & 38 & 0,457 & \multirow{3}{*}{81,8} \\
\hline & Negativo: $\leq 0,5 \mathrm{~cm}$ & 1 & 5 & 6 & $(0,187-0,727)$ & \\
\hline & Total & 32 & 12 & 44 & & \\
\hline
\end{tabular}

*Considerou-se como reação positiva a presença de granulomas unicêntricos ou multicêntricos, com ou sem mineralização central, ou a presença de histiócitos, com ou sem formação de células multinucleadas.

$\mathrm{IC}=$ intervalo de confiança.

Tabela 3. Teste de concordância entre o exame com tuberculina (tub.) PPD aviária, pela medição da espessura da dobra da pele, e o exame patológico, em suínos infectados naturalmente com MAC

\begin{tabular}{|c|c|c|c|c|c|c|}
\hline \multirow[t]{2}{*}{ Teste } & \multirow{2}{*}{$\begin{array}{l}\text { Critério usado } \\
\text { (ponto de corte) }\end{array}$} & \multicolumn{2}{|c|}{$\begin{array}{c}\text { Exames macro } \\
\text { e/ou micro }\end{array}$} & \multirow[t]{2}{*}{ Total } & \multirow{2}{*}{$\begin{array}{l}\text { Kappa } \\
\text { (IC) }\end{array}$} & \multirow{2}{*}{$\begin{array}{l}\text { Concordância } \\
\text { observada (\%) }\end{array}$} \\
\hline & & Positivo* & Negativo & & & \\
\hline \multirow{3}{*}{$\begin{array}{l}\text { Reação à tub. } \\
\text { aviária }\end{array}$} & Positivo: $>0,50 \mathrm{~cm}$ & 53 & 6 & 59 & 0,162 & \multirow{3}{*}{68,2} \\
\hline & Negativo: $\leq 0,50 \mathrm{~cm}$ & 22 & 7 & 29 & $(-0,021-0,346)$ & \\
\hline & Total & 75 & 13 & 88 & & \\
\hline \multirow{3}{*}{$\begin{array}{l}\text { Reação à tub. } \\
\text { aviária }\end{array}$} & Positivo: $>0,30 \mathrm{~cm}$ & 61 & 8 & 69 & 0,166 & \multirow{3}{*}{75,0} \\
\hline & Negativo: $\leq 0,30 \mathrm{~cm}$ & 14 & 5 & 19 & $(-0,037-0,370)$ & \\
\hline & Total & 79 & 13 & 88 & & \\
\hline \multirow{3}{*}{$\begin{array}{l}\text { Reação à tub. } \\
\text { aviária }\end{array}$} & Positivo: $>0,20 \mathrm{~cm}$ & 67 & 10 & 77 & 0,133 & \multirow{3}{*}{79,5} \\
\hline & Negativo: $\leq 0,20 \mathrm{~cm}$ & 8 & 3 & 11 & $(-0,075-0,340)$ & \\
\hline & Total & 75 & 13 & 88 & & \\
\hline
\end{tabular}

*Considerou-se como reação positiva a presença de granulomas unicêntricos ou multicêntricos, com ou sem mineralização central, ou a presença de histiócitos, com ou sem formação de células multinucleadas.

$\mathrm{IC}=$ intervalo de confiança. 
Tabela 4. Teste de concordância entre o exame com tuberculina (tub.) PPD aviária, pela medição da espessura da dobra da pele, e o exame patológico, em suínos infectados experimentalmente com MAC

\begin{tabular}{|c|c|c|c|c|c|c|}
\hline \multirow[t]{2}{*}{ Teste } & \multirow[t]{2}{*}{ Critério usado } & \multicolumn{2}{|c|}{$\begin{array}{c}\text { Exames macro } \\
\text { e/ ou micro }\end{array}$} & \multirow[t]{2}{*}{ Total } & \multirow{2}{*}{$\begin{array}{l}\text { Kappa } \\
\text { (IC) }\end{array}$} & \multirow{2}{*}{$\begin{array}{l}\text { Concordância } \\
\text { observada (\%) }\end{array}$} \\
\hline & & Positivo * & Negativo & & & \\
\hline \multirow{3}{*}{$\begin{array}{l}\text { Reação à tub. } \\
\text { aviária }\end{array}$} & Positivo: $>0,50 \mathrm{~cm}$ & 5 & 0 & 5 & 0,111 & \multirow{3}{*}{40,0} \\
\hline & Negativo: $\leq 0,50 \mathrm{~cm}$ & 12 & 3 & 15 & $(-0,090-0,312)$ & \\
\hline & Total & 17 & 3 & 20 & & \\
\hline \multirow{3}{*}{$\begin{array}{l}\text { Reação à tub. } \\
\text { aviária }\end{array}$} & Positivo: $>0,30 \mathrm{~cm}$ & 14 & 0 & 20 & 0,583 & \multirow{3}{*}{85,0} \\
\hline & Negativo: $\leq 0,30 \mathrm{~cm}$ & 3 & 3 & 6 & $(0,185-0,982)$ & \\
\hline & Total & 17 & 3 & 20 & & \\
\hline \multirow{3}{*}{$\begin{array}{l}\text { Reação à tub. } \\
\text { aviária }\end{array}$} & Positivo: $>0,20 \mathrm{~cm}$ & 17 & 1 & 18 & 0,773 & \multirow{3}{*}{95,0} \\
\hline & Negativo: $\leq 0,20 \mathrm{~cm}$ & 0 & 2 & 2 & $(0,346-1,200)$ & \\
\hline & Total & 17 & 3 & 20 & & \\
\hline
\end{tabular}

*Considerou-se como reação positiva a presença de granulomas unicêntricos ou multicêntricos, com ou sem mineralização central, ou a presença de histiócitos, com ou sem formação de células multinucleadas.

$\mathrm{IC}=$ intervalo de confiança.

Charette et al. (1989) e Guadagnini et al. (1997) consideraram animais positivos quando a reação à tuberculina PPD aviária foi igual ou maior que $1 \mathrm{~cm}$ no diâmetro, 48 horas após a aplicação. De 28 suínos de terminação que foram positivos nesse teste, Charette et al. (1989) encontraram lesões nos linfonodos em todos eles. Guadagnini et al. (1997) observaram que a freqüência de reatores foi maior entre os suínos em terminação do que em reprodutores e encontraram lesões macroscópicas em 53,5\% dos suínos positivos à tuberculina PPD aviária na fase de terminação. Songer et al. (1980) consideraram positivos os animais com reação igual ou superior a $1,2 \mathrm{~cm}$ de diâmetro, 48 horas após a aplicação de $0,1 \mathrm{ml}$ de PPD aviário. Eles encontraram correlação de $97,1 \%$ entre o teste de tuberculina intradérmico e a presença de lesões nos linfonodos de suínos ao abate.

Os melhores resultados de concordância nos suínos inoculados em relação aos infectados naturalmente, nos dois métodos avaliados, devem-se provavelmente ao fato de que, em condições naturais, não se conhece a dose de infecção e nem o tempo decorrido após a infecção. A relação entre a reação ao teste de tuberculina e a observação de lesões no abatedouro depende de alguns fatores, principalmente do período decorrido entre a infecção e a realização do exame macroscópico e da dose infectante. A linfadenite granulomatosa causada por MAC é de evolução crônica, podendo levar até quatro meses para o aparecimento das lesões macroscópicas (Thoen, 1992), enquanto a reação à tuberculina pode ocorrer a partir de 28 dias após a infecção com o MAC (Muscoplat et al., 1975). Então, em um rebanho, podem-se encontrar animais positivos ao teste intradérmico, mas que ainda não desenvolveram lesões macroscópicas. Isso pode ter ocorrido com alguns dos animais do experimento 1. Além do tempo decorrido após a infecção, devem-se considerar algumas condições para que ocorra desenvolvimento das lesões granulomatosas, como a dose infectante e a virulência da cepa bacteriana, pois doses infectantes baixas e cepas de $M$. avium pouco virulentas podem sensibilizar os animais, produzindo pequenas reações ao teste de tuberculina sem que se desenvolvam lesões visíveis (Tammemagi et al., 1971; Jorgensen, 1978).

No experimento 1, as médias das reações obtidas com a tuberculina aviária foram maiores que as médias das reações à tuberculina bovina, nos dois métodos testados (Tab. 5 e Fig. 7 e 8).

As médias das reações, foram maiores $(\mathrm{P}<0,05)$ à tuberculina PPD aviária, comparativamente à tuberculina bovina, nos suínos infectados natural e experimentalmente com MAC (Tab. 6). Mas, por razões práticas e econômicas, recomenda-se a utilização do método da medição do diâmetro maior das reações. 
Tabela 5. Diâmetro e aumento da espessura na dobra da pele das reações às tuberculinas aviária e bovina em suínos positivos de rebanhos infectados naturalmente com MAC

\begin{tabular}{lccccc}
\hline \multirow{2}{*}{ Granja } & \multirow{2}{*}{$\begin{array}{c}\text { Número de } \\
\text { animais } \\
\text { reagentes }\end{array}$} & $\begin{array}{c}\text { Diâmetro maior* } \\
\text { Tuberculina PPD } \\
\text { aviária }\end{array}$ & $\begin{array}{c}\text { Tuberculina PPD } \\
\text { bovina }\end{array}$ & $\begin{array}{c}\text { Tuberculina PPD } \\
\text { aviária }\end{array}$ & $\begin{array}{c}\text { Tuberculina PPD } \\
\text { bovina }\end{array}$ \\
\cline { 3 - 6 } & 35 & Média $(\mathrm{cm})$ & Média $(\mathrm{cm})$ & Média $(\mathrm{cm})$ & Média $(\mathrm{cm})$ \\
\hline 5 & 8 & 3,25 & 2,40 & NR & NR \\
7 & 1,09 & 1,51 & 0,48 & 0,34 \\
11 & 30 & 1,85 & 1,19 & 1,43 & 0,68 \\
12 & 37 & 2,39 & 1,46 & 1,14 & 0,59 \\
13 & 2 & 1,68 & 1,22 & 1,44 & 0,97 \\
14 & 2,20 & 0,83 & 1,73 & 0,26 \\
\hline
\end{tabular}

*Medição feita com régua milimétrica, 48 horas após a aplicação das tuberculinas; somente suínos com reações superiores a $0,5 \mathrm{~cm}$. **Medição com cutímetro, 48 horas após a aplicação das tuberculinas; somente suínos com reações superiores a $0,2 \mathrm{~cm}$.

NR: não realizado.

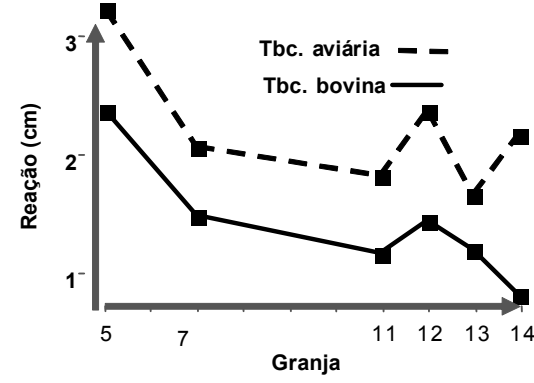

Figura 7. Valores médios do diâmetro das reações positivas em rebanhos infectados naturalmente por MAC.

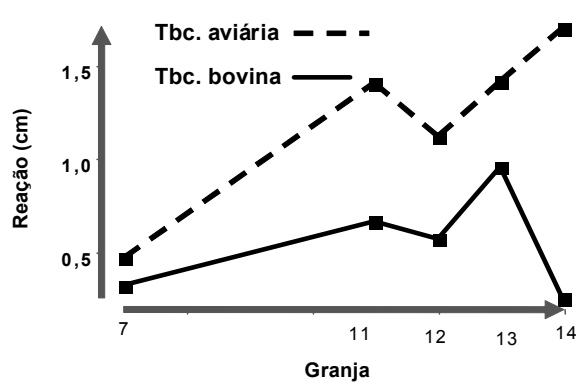

Figura 8. Valores médios do aumento na espessura da pele dos positivos em rebanhos suínos infectados naturalmente por MAC.

Tabela 6. Valores médios das reações às tuberculinas PPD aviária e bovina em suínos de rebanhos infectados naturalmente ${ }^{1}$ e em suínos inoculados com MAC ${ }^{2}$

\begin{tabular}{lccccc}
\hline \multirow{2}{*}{ Experimento } & \multirow{2}{*}{ Tuberculina } & \multicolumn{3}{c}{ Medida da reação à tuberculina PPD aviária } \\
\cline { 3 - 6 } & & \multicolumn{2}{c}{ Diâmetro maior* } & Aumento da espessura da pele** \\
\cline { 3 - 6 } & Aviária & 119 & Média, cm & $\mathrm{N}$ & Média, cm \\
\hline Infecção natural $^{1}$ & Bovina & $114^{* * *}$ & $2,40 \mathrm{a}$ & 77 & $1,42 \mathrm{a}$ \\
& Aviária & 38 & $2,64 \mathrm{~b}$ & 77 & $0,82 \mathrm{~b}$ \\
Infecção com MAC $^{2}$ & Bovina & 38 & $1,48 \mathrm{a}$ & 18 & $0,44 \mathrm{a}$ \\
& & 38 & 18 & $0,30 \mathrm{~b}$
\end{tabular}

* Medição feita com régua no diâmetro maior da reação; somente suínos com reações superiores a $0,5 \mathrm{~cm}$.

** Medição com cutímetro, 48 horas após a aplicação das tuberculinas; somente suínos com reações superiores a $0,2 \mathrm{~cm}$.

***Em cinco suínos, a medida não foi realizada.

Médias na mesma coluna com letras distintas diferem entre si $(\mathrm{P}<0,05)$ pelo teste Tukey.

Em suínos vivos, os resultados indicaram que o teste intradérmico é útil no diagnóstico da infecção com base no rebanho, mas pode falhar na detecção individual de suínos infectados com MAC, semelhante às observações de Szabó et al. (1975) e Guadagnini et al. (1997). Quando foram comparadas as médias das reações às tuberculinas PPD aviária e bovina, em rebanhos suínos infectados natural e experimentalmente com MAC, verificou-se que a média das reações à tuberculina PPD aviária foi sempre maior que a bovina. Pullar e Rushford (1954) verificaram que 
todos os animais inoculados com $M$. avium apresentaram maior reação à tuberculina PPD aviária do que à tuberculina e vice-versa. Segundo Cavirani et al. (1996), muitos suínos positivos ao teste intradérmico com PPD e/ou ao Elisa, quando abatidos, não apresentam lesões visíveis de linfadenite granulomatosa. Prichard et al. (1977), ao utilizarem a prova intradérmica em suínos de diferentes idades, infectados com MAC, verificaram que a maior percentagem de animais positivos foi obtida com suínos em idade de abate.

A interpretação individual do teste intradérmico não é satisfatória, pois pode apresentar percentual variável de falsos positivos e falsos negativos em um rebanho. A baixa acurácia do teste tuberculínico intradérmico individual pode ser atribuída a: perda de reatividade entre o MAC infectante e o MAC utilizado na preparação da tuberculina (Songer et al., 1980); administração incorreta da tuberculina; erro na leitura (Songer et al., 1980); presença de animais recentemente infectados, mas que ainda não desenvolveram hipersensibilidade à PPD (Muscoplat et al., 1975); infecção por mais de um tipo de MAC num mesmo rebanho (Szabó et al., 1975); falhas no processo de inspeção patológica (Pullar e Rushford, 1954); dessensibilização dos animais

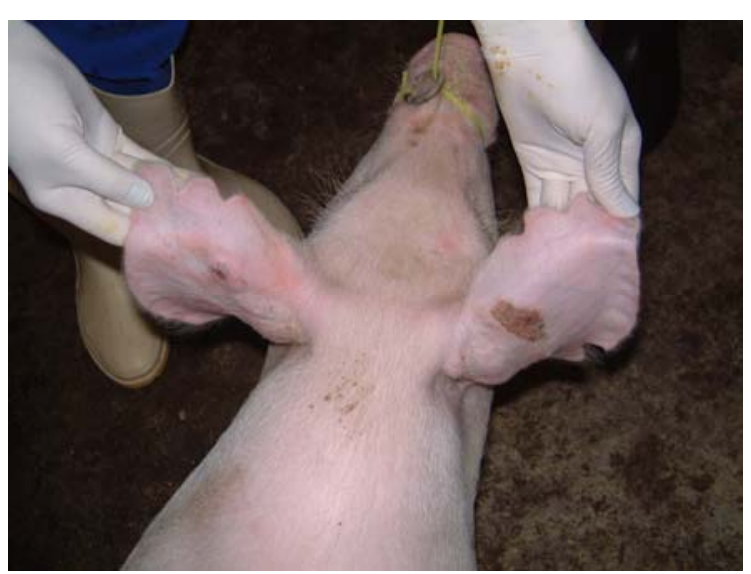

Figura 9. Suíno inoculado com $M$. bovis: reação positiva à tuberculina aviária (orelha esquerda) maior que a reação à bovina. Nota-se necrose grave (orelha direita).
(Pullar e Rushford, 1954); reações cruzadas com outras espécies de micobactérias e outros gêneros bacterianos como Rodococcus equi (Thoen et al., 1992; Oliveira et al., 1996); regressão das lesões por MAC (Pullar e Rushford, 1954; Cavirani et al., 1996); e a animais anérgicos (Abbas et al., 1995).

Os suínos inoculados com M. bovis (exp. 3) reagiram às duas tuberculinas aplicadas (Fig. 9), mas as reações foram sempre maiores à tuberculina bovina, tanto na medida do diâmetro quanto no aumento da espessura da pele (Tab. 7). Dos oito inoculados, seis apresentaram lesões tuberculosas nos pulmões (Fig. 10), uma característica não verificada nos suínos infectados com MAC.

Oliveira et al. (1996), ao usarem os mesmos critérios do teste em inoculações experimentais, observaram que as reações à tuberculina PPD bovina foram maiores do que para a aviária no grupo inoculado com o $M$. bovis. O inverso ocorreu com os inoculados com MAC. Muscoplat et al. (1975) usaram o mesmo critério e observaram que a maior reação ocorreu com PPD homóloga. Verificaram também que aos 55 dias houve maior reação que aos 28 dias da inoculação.

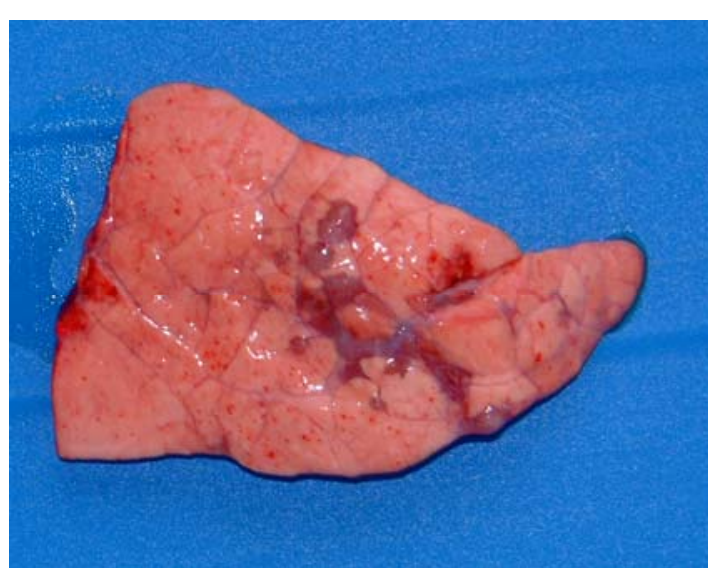

Figura 10. Suíno inoculado com M. bovis: lesões tuberculosas no parênquima pulmonar. 
Tabela 7. Resultados individuais das reações às tuberculinas PPD aviária e bovina e lesões macroscópicas em suínos inoculados com M. bovis, 40 dias pós-inoculação

\begin{tabular}{|c|c|c|c|c|c|c|c|}
\hline \multirow[t]{2}{*}{ Tratamento } & \multirow[t]{2}{*}{ Suíno } & \multicolumn{2}{|c|}{$\begin{array}{l}\text { Diâmetro da reação } \\
\left(\mathrm{cm}^{*}\right)\end{array}$} & \multicolumn{2}{|c|}{$\begin{array}{l}\text { Aumento da espessura da pele } \\
\qquad\left(\mathrm{cm}^{* *}\right)\end{array}$} & \multicolumn{2}{|c|}{ Lesões } \\
\hline & & Aviária & Bovina & Aviária & Bovina & Pulmões & Linfonodos \\
\hline \multirow{9}{*}{ Inoculado } & 463 & 3,0 & 4,0 & 0,32 & 1,01 & + & $\mathrm{MD}$ \\
\hline & 464 & 3,0 & 7,0 & 0,22 & 0,80 & + & MD \\
\hline & 465 & 5,0 & 7,0 & 0,47 & 1,10 & + & MD \\
\hline & 466 & 3,0 & 7,0 & 0,27 & 0,54 & + & MD \\
\hline & 467 & 2,5 & 4,0 & 0,25 & 1,15 & + & MD \\
\hline & 468 & 3,0 & 6,5 & 0,17 & 1,38 & Neg. & MD \\
\hline & 469 & 3,5 & 5,0 & 0,38 & 0,47 & + & MD \\
\hline & 470 & 3,0 & 7,0 & 0,32 & 1,05 & + & MD \\
\hline & Média & $3,2 \mathrm{a}$ & $5,9 b$ & $0,30 \mathrm{a}$ & $0,94 b$ & & \\
\hline \multirow{4}{*}{ Controle } & 443 & 0,5 & 0,1 & 0,0 & 0,0 & Neg. & Neg. \\
\hline & 445 & 0,5 & 0,5 & 0,0 & 0,1 & Neg. & Neg. \\
\hline & 449 & 0,5 & 0,3 & 0,0 & 0,0 & Neg. & Neg. \\
\hline & 450 & 0,5 & 0,5 & 0,0 & 0,0 & Neg. & Neg. \\
\hline
\end{tabular}

* Medição feita com régua no diâmetro maior da reação.

**Diferença entre as medidas (posterior-anterior) feita com cutímetro dobrando-se a pele no centro da reação.

Médias na mesma linha com letras distintas diferem entre si $(\mathrm{P}<0,05)$ pelo teste Tukey.

$\mathrm{MD}=$ linfonodos mediastínicos.

No teste intradérmico comparado, quando se usou PPD aviário e PPD bovino, foi possível identificar rebanhos infectados com MAC, calculando-se a média das reações dos animais positivos para qualquer uma das tuberculinas. A diferença entre as médias sempre foi maior quando o rebanho estava infectado por MAC. Essa diferença foi mais evidente em suínos inoculados com MAC (exp. 2). As recomendações para interpretação das reações às tuberculinas, com prova comparada utilizando tuberculinas bovina e aviária, contidas na Instrução Normativa número 19, de 15 de fevereiro de 2002, da Secretaria de Defesa Agropecuária, estão de acordo com os resultados obtidos neste trabalho.

De modo geral, um resultado positivo no teste de tuberculina é um bom auxílio diagnóstico para identificar rebanhos infectados, mas dúvidas persistem sobre quais critérios usar para definir uma reação como positiva com base no indivíduo.

\section{CONCLUSÕES}

É possível diferenciar rebanhos suínos infectados com MAC ou com $M$. bovis pelo teste intradérmico comparado, utilizando-se PPD aviário e bovino, embora ocorra reação cruzada entre eles. As reações alérgicas superiores a $0,5 \mathrm{~cm}$ no diâmetro maior ou $0,20 \mathrm{~cm}$ no aumento da espessura da dobra da pele devem ser consideradas positivas para cálculo da média em um rebanho. As medidas do diâmetro maior e do aumento da espessura da dobra da pele das reações alérgicas foram igualmente eficientes no diagnóstico de rebanhos infectados com MAC ou com M. bovis.

\section{REFERÊNCIAS BIBLIOGRÁFICAS}

ABBAS. A.K.; LICHTMAN, A.H.; POBER, J.S. Imunologia celular e molecular. 2.ed. Rio de Janeiro: Revinter, 1995. 440p.

CAVIRANI, S.; GUADAGNINI, P.F.; ALBORALI, L. et al. Intradermal tuberculin test (IDT), Elisa and Western blots in pigs naturally infected with Mycobacterium avium. In: INTERNACTIONAL PIG VETERINARY SOCIETY CONGRESS, 14., 1996, Bologna. Proceedings... Bologna: IPVS, 1996. p.338.

CHARETTE, R.; MARTINEAU, G.P.; PIGEON, C. et al. An outbreak of granulomatous lynfadenitis due to Mycocterium avium in swine. Can. Vet. J., v.30, p.675-678, 1989.

GUADAGNINI, P.F.; ALBORALI, L.; LOMBARDI, G. et al. Tuberculosis and 
mycobacteriosis in swine. The approach to the outbreak. In: MEETING REPORT DE LA SOCIETÁ ITALIANA DE PATOLOGIA SUÍA, 23., 1977, Parma. Proceedings..., Parma: Benedettina Editrice, 1977. p.167-176.

JORGENSEN, J.B. Experimental infection with Mycobacterium avium, serotype 2 in pigs. Acta Vet. Scand., v.19, p.49-57, 1978.

MARTINS, L.S. Epidemiologia e controle das micobacterioses em suínos no sul do Brasil: Estimativa do impacto econômico e estudo da sazonalidade. 2001. 51f. Dissertação (Mestrado em Epidemiologia Experimental) - Faculdade de Medicina Veterinária e Zootecnia, Universidade de São Paulo, São Paulo.

MORÉS, N.; VENTURA, L.V.; VIDAL, C.E.S. et al. Uso da técnica de imunoperoxidase em cortes histológicos incluídos em parafina para diagnóstico da linfadenite causada pelo Mycobacterium do complexo avium. In: CONGRESSO BRASILEIRO DE VETERINÁRIOS ESPECIALISTA EM SUÍNOS, 10., 2001, Porto Alegre. Anais... Concórdia: Embrapa Suínos e Aves, 2001. p.139-140.

MUSCOPLAT, C.C.; THOEN C.O.; CHEN, A.C. et al. Development of specific lynfocyte immunosstimulation and tuberculin reativity tuberculin skin reativity in swine infected with Mycobacterium bovis and Mycobacterium avium. Am. J. Vet. Res., v.36, p.1167-1171,1975.

OLIVEIRA S.J.; CHEONG, F.; GIANOULAKIS, M.K. et al. Testes de Elisa e intradérmico para diagnóstico de infecção por micobactérias e Rhodococcus equi, em suínos infectados experimentalmente. Arq. Bras. Med. Vet. Zootec., v.48, p.249-257, 1996.

PRICHARD, W.D.; THOEN, C.O.; HIMES, E. et al. Epidemiology of mycobacterial lynphadenitis in an Idaho swine herd. Am. J. Epidemiol., v.106, p.222-227, 1977.

PULLAR, E.M.; RUSHFORD, B.H. The accuracy of the avian intradermal tuberculin test in pigs. Austr. Vet. J., v.8, p. 221-231, 1954.

SENK, L.; POGACNILK, M.; BOEHM, O. Patology of experimental Mycobacterium intracellulare serovar 4 infection in the pig. In : INTERNATION PIG VETERINARY SOCIETY CONGRESS, 12., 1992, The Hague. Proceedings... The Hague: IPVS, 1992. p 342.

SILVA, V.S. Estudo da transmissão horizontal de Mycobacterium avium-intracellulare em suínos. 1998. 47f. Dissertação (Mestrado em Sanidade Animal) - Faculdade de Veterinária da Universidade Federal de Pelotas, Pelotas, RS.

SONGER, J.G.; BICKNELL, E.J.; THOEN, C.O. Epidemiological investigation of swine tuberculosis in Arizona. Can. J. Comp. Med. , v.44, p.115-120, 1980 .

SYSTEM for Microsoft Windows: release 8.2, Cary, NC: SAS Institute, 2001. CD ROM.

SZABÓ, I.; TUBOLY, S.; SZÉKY, et al. Swine lymphadenitis due to Mycobacterium avium and atypical mycobacteria. Acta Vet. Acad. Scient. Hung., v.25, p.77-83, 1975.

TAMMEMAGI, L.; SIMMONS, G.C. Pathogenicity of Mycobacterium intracellulare to pigs. Austr. Vet. J., v.47, p.337-339, 1971

THOEN, C.O. Tuberculosis. In: LEMAN, A.D.; STRAW, B.E., MENGELING, W.L. et al. (Eds.). Diseases of swine. Ames: Iowa State University, 1992. p. 617-26.

WIN Episcope 2.0. Disponível em: $<$ http:www.clive.ed.ac.uk/winepiscope $>$.

Acessado em: 18 ago. 2004. 